Volume 10 No. 2 September 2019

P-ISSN 2086-6178 E-ISSN 2579-3292

http://ejournal.bsi.ac.id/ejurnal/index.php/jkom

\title{
Perancangan Animasi Stopmotion Pangeran Diponegoro Berbasis Sinematografsi
}

\author{
Supriyadi \\ STMIK NUSA MANDIRI Jakarta \\ spy2adi@gmail.com
}

Cara Sitasi: Supriyadi. Perancangan Animasi Stopmotion Pangeran Diponogoro Berbasis Sinematografi. Jurnal Komunikasi 10(2). 145-152.

\begin{abstract}
Nowadays animated films are developing rapidly in Indonesia. Animated films are in demand because they are entertaining, but rarely found educative animated films that tell about history. In general, historical documentation is only based on thick textbooks, and the placement of photos of heroes on classroom walls is generally not interesting for students to enjoy. This encourages researchers to make an animated film that has historical and educational value. With appropriate cinematography, a film can have high artistic value. In addition, the film can also convey information and implied messages that can be used as lessons in life. To attract students, stopmotion technique was chosen. This stopmotion animation is created by applying the sine matography technique so that what will be conveyed in this animated film can be conveyed well to the audience. All of this aims to make the animation look livelier, smoother in its movements, and produce a more attractive appearance and is liked by the audience. It is better to make a stopmotion animation in a detailed storyboard design, so there are no mistakes when making motion, camera angles, type shots, and video translation. Stopmotion filmmaking is inseparable from photography and cinematography.
\end{abstract}

Keywords: animation, stopmotion, sinematografi

\section{PENDAHULUAN}

Pangeran Diponegoro adalah putra sulung dari Sultan Hamengkubuwana III, raja ketiga di Kesultanan Yogyakarta. Lahir pada tanggal 11 November 1785 di Yogyakarta dengan nama Mustahar dari seorang selir bernama R.A. Mangkarawati, yang berasal dari Pacitan. Semasa kecilnya, Pangeran Diponegoro bernama Bendara Raden Mas Antawirya.Diponegoro lebih tertarik pada kehidupan keagamaan dan merakyat sehingga ia lebih suka tinggal di Tegalrejo tempat tinggal eyang buyut putrinya, permaisuri dari Sultan Hamengkubuwana I, Gusti Kangjeng Ratu Tegalrejo, daripada di keraton.

Perang Diponegoro berawal ketika pihak Belanda memasang patok di tanah milik Diponegoro di desa Tegalrejo. Saat itu, ia memang sudah muak dengan kelakuan Belanda yang tidak menghargai adat istiadat setempat dan sangat mengeksploitasi rakyat dengan pembebanan pajak.

Sikap Diponegoro yang menentang Belanda secara terbuka, mendapat simpati dan dukungan rakyat. Atas saran GPH Mangkubumi, pamannya, Diponegoro menyingkir dari Tegalrejo, dan membuat markas di sebuah gua yang bernama Gua Selarong. Saat itu, Diponegoro menyatakan bahwa perlawanannya adalah perang sabil, perlawanan menghadapi kaum kafir. Semangat "perang sabil" yang dikobarkan Diponegoro membawa pengaruh luas hingga ke wilayah Pacitan dan Kedu. Salah seorang tokoh agama di Surakarta, Kyai Maja, ikut bergabung dengan pasukan Diponegoro di Gua Selarong. Kyai Mojo yang lahir di Desa Mojo di wilayah Pajang, dekat Kota Surakarta tertarik berjuang bersama Pangeran Diponegoro karena Pangeran Diponegoro ingin mendirikan kerajaan yang berlandaskan Islam. Kyai Mojo dikenal sebagai ulama besar yang sebenarnya masih memiliki hubungan kekerabatan dengan Diponegoro. Ibu Kyai Mojo, R.A. Mursilah, adalah saudara perempuan dari Sultan Hamengkubuwana III. Akan tetapi, Kyai Mojo yang aslinya bernama Muslim Mochamad Khalifah semenjak lahir tidak mencicipi kemewahan gaya hidup keluarga istana. Jalinan persaudaraan Diponegoro dan Kyai Mojo kian erat setelah Kyai Mojo menikah dengan janda Pangeran Mangkubumi yang merupakan paman dari Diponegoro. Tak heran, Diponegoro memanggil Kyai Mojo dengan sebutan "paman" meski relasi keduanya adalah saudara sepupu.

Selain Kyai Mojo, perjuangan Diponegoro juga didukung oleh Sunan Pakubuwono VI dan Raden Tumenggung Prawiradigdaya Bupati Gagatan. Meski demikian, pengaruh dukungan 
Kyai Mojo terhadap perjuangan Diponegoro begitu kuat karena ia memiliki banyak pengikut dari berbagai lapisan masyarakat. Kyai Mojo yang dikenal sebagai ulama penegak ajaran Islam ini bercita-cita, tanah Jawa dipimpin oleh pemimpin yang mendasarkan hukumnya pada syariat Islam. Semangat memerangi Belanda yang merupakan musuh Islam dijadikan taktik Perang Suci. (Peter, 2016)

\section{Animasi}

Animasi yang berasal dari Bahasa Yunani Anima yang berarti memberi nyawa. Sedangkan animasi sendiri yaitu sebuah film dari benda yang seolah hidup, terbuat dari fotografi, gambar, boneka atau tulisan, dengan perbedaan tipis antar frames, untuk memberi kesan pergerakan saat diproyeksikan. Secara umum animasi bisa dikatakan sebagai sebuah tayangan yang memanfaatkan permainan dari perbedaan gerakan dari beberapa gambar yang sudah ada sehingga membentuk suatu ilusi gerakan yang dinamis dan nyata. Melalui proses-proses yang dilalui, gambar yang telah ada disatukan sehingga menghasilkan sebuah gerakan yang alami. (W. Nugroho, 2011)

Animasi pada saat ini banyak dimanfaatkan untuk berbagai kebutuhan dalam berbagai kegiatan baik untuk kegiatan yang bersifat formal maupun rekreatif. Pemakaian unsur animasi di dalam sebuah aplikasi mult imedia sangat menjanjikan suatu tampilan visual yang lebih dinamis, dapat menampilakan sesuatu tampilan visual yang imajinatif dan mustahil dalam kehidupan yang sebenarnya tetapi dapat divisualisasikan secara meyakinkan dalam animasi.

Prinsip dasar animasi adalah Prinsip-prinsip yang digunakan seorang animator untukmengetahui dan memahami bagaimana sebuah animasi dibuat sedemikian rupa sehingga didapatkan hasil animasi yang menarik, dinamis dan tidak membosankan. Prinsip dasar ini animasi ini sebenarnya paling pas digunakan untuk animasi kartun.Modal utama seorang animator adalah kemampuan meng-capture momentum ke dalam runtutan gambar sehingga seolah-olah menjadi bergerak atau hidup. Sedikit berbeda dengan komikus, ilustrator, atau -katakanlahkarikaturis yang menangkap suatu momentum ke dalam sebuah gambar diam (still). Animator harus lebih memiliki 'kepekaan gerak' daripada 'hanya' sekedar kemampuan menggambar. Gambar yang bagus akan percuma tanpa didukung kemampuan meng-'hidup'-kan. Sebagaimana definisi dasar animasi yang berarti: membuat seolah-olah menjadi hidup.

Alasan penulis menggunakan teknik stopmotion dalam pembuatannya, yaitu:

1. Teknik stopmotion menggunakan kreatifitas yang tinggi dalam pembuatan karakter dan desain gambar.

2. Teknik stopmotion menggabungkan berbagai teknik

pengolah media seperti desain grafis, teknologi audio, teknologi video, sinematografi, animasi, fotografi.

Stopmotion memiliki beberapa kelebihan, berikut kelebihan penggunaan teknik stopmotion:

1. Tidak menggunakan banyak gambar

2. Tidak memerlukan peralatan yang sulit

3. Kreatifitas dalam pembuatan desain objek dan pengembangan animasi.

\section{Sinematografi}

Menurut Kamus Ilmiah Serapan Bahasa Indonesia Sinematografi diartikan sebagai ilmu dan teknik pembuatan film atau ilmu, teknik, dan seni pengambilan gambar film dengan menggunakan alat perekam. Film atau Cinema merupakan produk atau buah karya dari kegiatan sinematografi. Film sebagai karya sinematografi merupakan hasil perpaduan antara kemampuan seseorang atau sekelompok orang dalam penguasaan teknologi, olah seni, komunikasi, dan manajemen berorganisasi. (Naratama Rukmananda, 2014)

Secara detail keempat kompetensi tersebut berikut ruang lingkupnya dapat disajikan dalam Tabel berikut.

Tabel 1. Komposisi Sinematografi

\begin{tabular}{|l|l|l|}
\hline No & Kompetensi & Ruang Lingkup \\
\hline 1 & Teknologi & $\begin{array}{l}\text { Teknologi optik, } \\
\text { mekanik, hingga olah } \\
\text { digital }\end{array}$ \\
\hline 2 & Olah Seni & $\begin{array}{l}\text { Peran(drama), tata } \\
\text { cahaya(warna), tata } \\
\text { suara, art desain } \\
\text { indoor/outdoor, dan } \\
\text { sebagainya }\end{array}$ \\
\hline 3 & Komunikasi & $\begin{array}{l}\text { Termasuk seluruh } \\
\text { komponen } \\
\text { komunikasi dan } \\
\text { teknik } \\
\text { penyampaiannya }\end{array}$ \\
\hline 4 & Manajemen & $\begin{array}{l}\text { Organisasi dan } \\
\text { komponennya, } \\
\text { termasuk manajemen } \\
\text { sumber daya manusia } \\
\text { (SDM), manajemen } \\
\text { anggaran, produksi, } \\
\text { dan pemasaran }\end{array}$ \\
\hline
\end{tabular}

Sinematografi memiliki objek yang sama dengan fotografi yakni menangkap pantulan cahaya yang mengenai benda. Karena objeknya sama maka peralatannyapun mirip. Perbedaannya, peralatan fotografi menangkap gambar tunggal, sedangkan sinematografi menangkap rangkaian gambar. 
Penyampaian ide pada fotografi memanfaatkan gambar tunggal, sedangkan pada sinematografi memanfaatkan rangkaian gambar. Jadi sinematografi adalah gabungan antara fotografi dengan teknik perangkaian gambar atau dalam sinematografi disebut montase (montage).

Sinematografi sangat dekat dengan film dalam pengertian sebagai media penyimpan maupun sebagai genre seni. Film sebagai media penyimpan adalah pias (lembaran kecil) selluloid yakni sejenis bahan plastik tipis yang dilapisi zat peka cahaya. Benda inilah yang selalu digunakan sebagai media penyimpan di awal pertumbuhan sinematografi. Film sebagai genre seni adalah produk sinematografi.. Sinematografi memiliki objek yang sama dengan fotografi yakni menangkap pantulan cahaya yang mengenai benda. Karena objeknya sama maka peralatannyapun mirip. Perbedaannya, peralatan fotografi menangkap gambar tunggal, sedangkan sinematografi menangkap rangkaian gambar. Penyampaian ide pada fotografi memanfaatkan gambar tunggal, sedangkan pada sinematografi memanfaatkan rangkaian gambar. Jadi sinematografi adalah gabungan antara fotografi dengan teknik perangkaian gambar atau dalam sinematografi disebut montase (montage).Sinematografi sangat dekat dengan film dalam pengertian sebagai media penyimpan maupun sebagai genre seni. Film sebagai media penyimpan adalah pias (lembaran kecil) selluloid yakni sejenis bahan plastik tipis yang dilapisi zat peka cahaya. Benda inilah yang selalu digunakan sebagai media penyimpan di awal pertumbuhan sinematografi. Film sebagai genre seni adalah produk sinematografi. (Naratama Rukmananda, 2014)

\section{METODOLOGI PENELITIAN}

Sebelumnya telah dibuat film animasi dengan judul "Penciptaan Karya Animasi Kobarkan Semangat Bung Tomo " oleh Lailatur Ristagama. (Lailatul Ristagama, 2014)

Film animasi tersebut sudah ada pembahasan mengenai pembuatan film animasi 2 dimensi mengenai sejarah tetapi belum ada pembahasan tentang stopmotion. Namun masih belum ada yang membahas secara spesifik mengenai penerapan sinematografi dalam pembuatan film stopmotion. Maka dari itu dibuatlah Film animasi edukasi yang dapat mengenalkan sejarah dengan menggunakan teknik yang modern, yaitu teknik stopmotion dengan judul Pangeran Diponegoro. Animasi ini dibuat dengan konsep stopmotion agar menarik untuk disajikan, sehingga semua orang tertarik untuk mempelajari cerita sejarah Pangeran Diponegoro. Film animasi ini dibuat dengan menerapkan prinsip animasi dan sinematografi sehingga nilai-nilai edukasi dan nilai-nilai seni dari film tersebut dapat tersampaikan kepada para penonton. (Ruslan, 2016)
Metode penelitian memiliki ruang yang sangat luas. Dilihat dari jenis penelitian, maka penelitian dapat dibedakan menjadi 3 klasifikasi, yaitu penelitian aplikatif, penelitian maksud, dan penelitian berdasarkan jenis informasi. Pada penelitian aplikatif, terdapat 2 jenis penelitian, yaitu penelitian murni dan terapan. Dalam pembuatan karya ini yang di gunakan adalah penelitian terapan. Penelitian terapan adalah penelitian yang hasilnya dapat digunakan langsung untuk menyelesaikan permasalahan yang di hadapi. (Arikunto, 2013)

Metode yang dapat digunakan didalam perancangan ini yaitu:

1. Tahap analisa

Tahapan analisa disini meliputi pengambilan data dari storyboard, dan referensi akan film animasi yang digunakan.

2. Perancangan Karya

Untuk tahapan perancangan karya yang digunakan adalah proses desain, proses pengumpulan material, menyusun frame, menggabungkan scene, export media dan mastering editing.

\section{HASIL DAN PEMBAHASAN}

Film Pangeran Diponegoro ini merupakan film animasi yang dibuat menggunakan teknik stopmotion, film animasi stopmotion ini ditujukan untuk kalangan pelajar yaitu pada usia 10-25 tahun, Film ini dibuat bertujuan sebagai media pembelajaran sejarah, sehingga animasi ini dibuat dengan menggunakan teknik yang baru dan menarik yaitu teknik stopmotion sehingga para penonton berminat dan tertarik untuk menyaksikan dan mempelajari sejarah dari Pangeran Diponegoro. Film animasi ini disajikan dengan menggunakan diorama sebagai desain latar berbentuk 3 dimensi dan menggunanan media kertas dalam bentuk 2 dimensi sebagai objek karakter yang kemudian digeserkan sedikit demi sedikit (frame by frame), kemudian di sempurnakan dengan editing mengunakan Adobe Premiere dan After Effect untuk pemberian efeknya, animasi ini juga di lengkapi dengan sountrack dan efek suara yang berkualitas.

\section{Tahap Analisa \\ Storyboad}

Storyboard merupakan kumpulan sketsa gambar yang disusun secara berurutan dan disesuaikan dengan naskahnya sehingga ide cerita bisa disampaikan dengan mudah. (Hart, 2008)

Di jaman sekarang storyboard dipakai di berbagai bidang, seperti perfilman, animasi, hingga dunia advertising. Pada prosesnya, sutradara dan pengarah fotografi akan membahas adegan-adegan secara lengkap, kemudian mereka akan menghubungi seniman storyboard untuk menerjemahkan idenya dalam rangkaian gambar. Dari sini akan tercipta rancangan shooting. Secara gamblangnya, storyboard 
ini akan memberikan gambaran jelas pada pemain serta kru supaya bisa bekerja dengan baik. Umumnya dalam storyboard ini ada tata letak visual adegan yang akan diambil. Tidak hanya itu, storyboard juga penting bagi editor agar ia bisa menyusun scene yang berbeda sesuai dengan skenario yang ditetapkan Dalam pembuatan storyboard, ada beberapa hal yang perlu diperhatikan, antara lain ; prinsip penulisan, konsep, strategi dan proses perancangan grafis. Prinsip penulisan storyboard yang baik adalah Pesan visual harus kreatif (asli, luwes dan lancar), komunikatif, efisien dan efektif, sekaligus indah/estetis. Sedangkan konsep, strategi dan proses perancangan grafis yang baik untuk storyboard adalah $5 \mathrm{~W}$ dan $1 \mathrm{H}$ (what, where, when, who, why dan how) serta mempunyai penyampaian pesan yang efektif dan efesien. (Dhimas, 2013).

Desain Storyboard pembuatan animasi Pangeran Diponegoro dapat dilihat pada gambar dibawah ini.

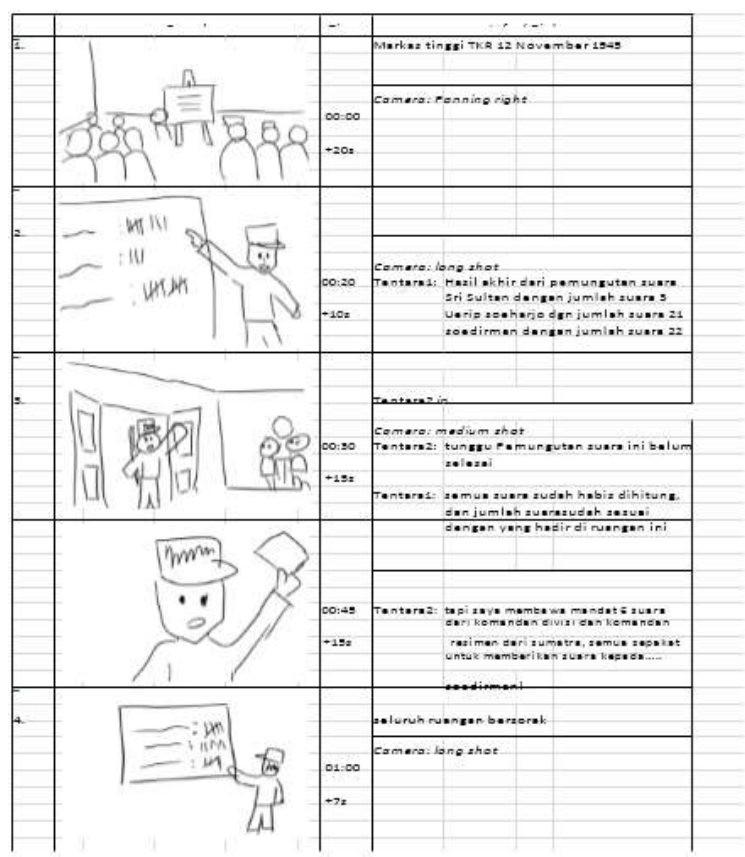

Gambar 1. Bentuk Storyboard

Material Collecting (Pengumpulan Materi)

Aset-aset yang dibutuhkan dalam pembuatan film animasi stopmotion Pageran Diponegoro ini, diambil dari aset yang telah dibuatkan dalam bentuk bonekaboneka.

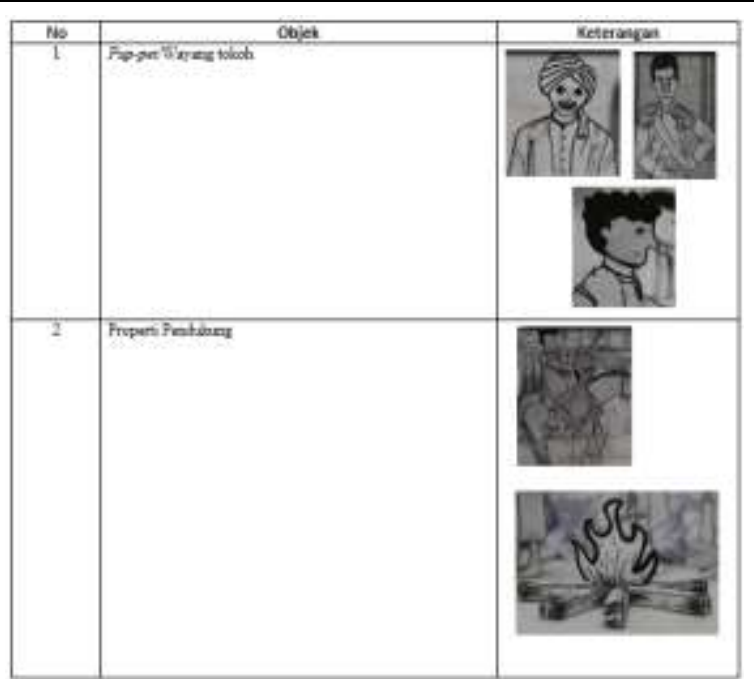

Gambar 2. Material Stopmotion

\section{Perancangan Karya}

Realisasi Produk Multimedia

Tahap realisasi ini merupakan fase Assembly dalam metode Luther. Setelah menyiapkan Storyboard dan aset-aset yang telah di kumpulkan pada tahap Material collecting, maka dapat di lanjutkan ke tahap realisasi. Adapun alur pembuatan film animasi stopmotion "Pangeran Diponegoro" ini, digambarkan dalam bentuk flowchart pada gambar berikut.

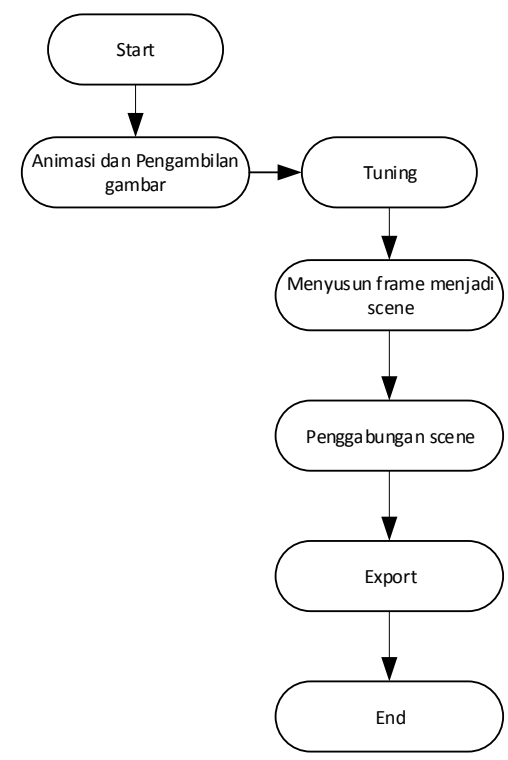

Gambar 3. Alur Pembuatan Animasi

\section{Animasi dan Pengambilan Gambar}

Tahap ini merupakan tahap dimana aset-aset yang telah dikumpulkan akan dianimasikan dan akan diambil gambarnya dengan teknik stopmotion (frame-by-frame) sesuai dengan storyboard yang telah dibuat. Proses animasi dilakukan dengan menerapkan perinsip animasi, dan pengambilan gambar dilakukan dengan menerapkan sinematografi, seperti angle camera, camera movement, dan type of 
shot. Pengambilan gambar dilakukan menggunakan kamera Canon DSLR EOS 700D yang menggukanan fitur Tethering disambungkan langsung ke software Adobe Lightroom 6. (Wary, 2010)

Adapun alat-alat pendukung yang digunakan dalam tahap pengambilan gambar yaitu, Tripod, Shoot Through Umbrella (flash payung), dan continuous lamp. Dengan fitur Tethering yang ada pada software Adobe Lightroom 6, kamera Canon DSLR EOS 700D dapat disambungkan menggunakan kabel tethering dapat dioperasikan secara langsung dari software Adobe Lightroom 6. Setelah melakukan pengaturan dan menyambungkan kabel tethering, maka akan muncul tethering navigation secara otomatis. Tethering navigation berfungsi sebagai pengaturan kamera, seperti pengaturan ISO, aperture, dan shuter speed. Selain menyiapkan software yang digunakan, diperlukan juga alat-alat pendukung, seperti, continous lamp, shot trough umbrella dan tripod, untuk menunjang dalam proses pengambilan gambar. Tahap selanjutnya adalah tahap animasi, dimana aset-aset yang telah dikumpulkan seperti, set diorama dan puppet/wayang dirangkai sedemikian rupa, sehingga sesuai dengan tampilan yang ada dalam desain storyboard. Setiap gerakan tubuh/gesture yang dianimasikan akan diambil gambarnya dengan teknik frame-by-frame. Agar objek yang dianimasikan terlihat seolah olah bergerak dengan sendirinya. Selain gerakan tubuh/gesture, juga diperlukan pembuatan gerakan mulut (lypsinc). Lypsinc dibuat dengan cara merubah kepala dari objek wayang, secara satu persatu, kemudian kembali diambil gambar dengan teknik frame-by-frame. (Peterson, 2010)
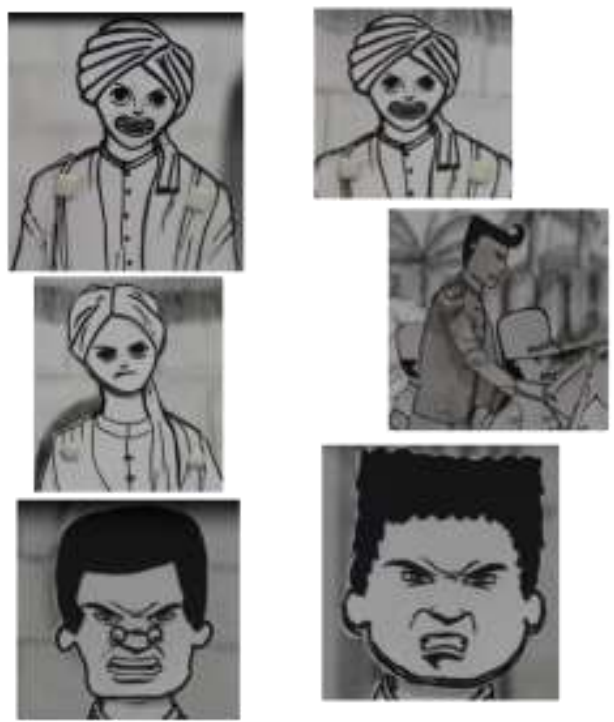

Gambar 4. Objek Aset
Setelah animasi dan pengambilan gambar, tahap selanjutnya adalah proses tunning gambar, bertujuan untuk mempertajam warna dari gambar yang telah diambil, proses tunning ini meliputi pengaturan brightness, contrast, curves, dan level yang ada pada software Adobe Lightroom 6. Pada Adobe Lightroom 6 terdapat fitur preset, preset adalah sample pengaturan yang diberikan oleh Adobe Lightroom untuk mempermudah pengguna dalam melakukan proses tunning. Selain mempertajam warna, dalam proses tunning ini juga dilakukan pemberian color effect. Untuk memberikan efek suasana malam hari untuk beberapa scene yang akan dibuat seakan-akan terjadi di malam hari. Pemberian color effect ini menggunakan fitur PenTool dan color lookup yang ada dalam software Adobe Photoshop CS6. Pentool digunakan untuk menseleksi area yang akan diberikan color effect dengan menggunakan fitur color lookup. Untuk mendapatkan color effect malam hari, dapat menggunakan color lookup Moonlight 3DL.(Perisic, 2013)

\section{Menyusun Frame Menjadi Scene}

Setelah gambar/frame telah di-tunning, maka dapat dilanjutkan ke tahap penyusunan frame menjadi sebuah scene. Tahap ini merupakan proses yang dilakuan untuk menyatukan semua frame menjadi satu scene. Frame-frame yang telah di ambil pada tahap animasi akan dimasukan ke software Adobe Premiere Pro CS6 kemudian digabungkan menjadi sebuah scene. Frame-frame yang saling berkaitan akan digabungkan menjadi sebuah scene, yaitu dengan cara nyusun frame-frame tersebut secara berurutan, sehingga gerakan-gerakan dari objek dapat terlihat gerakan aslinya.

\section{Penggabungan Scene}

Setelah semua frame-frame disusun menjadi scene, tahap selanjutnya yang dilakukan adalah, menggabungkan scene menjadi sebuah film animasi. Scene akan disusun sesuai dengan alur cerita yang telah ditentukan dalam storyboard. Setelah semua scene sudah tersusun sesuai dengan alur cerita yang telah di buat dalam storyboard, yang selanjutnya dilakukan adalah memberikan video translation diantara dua scene. Caranya dengan menggunakan fitur effect yang sudah tersedia di dalam software Adobe Premiere Pro CS6, yaitu video translation. (Hendratman, 2017)

\section{Tunning}




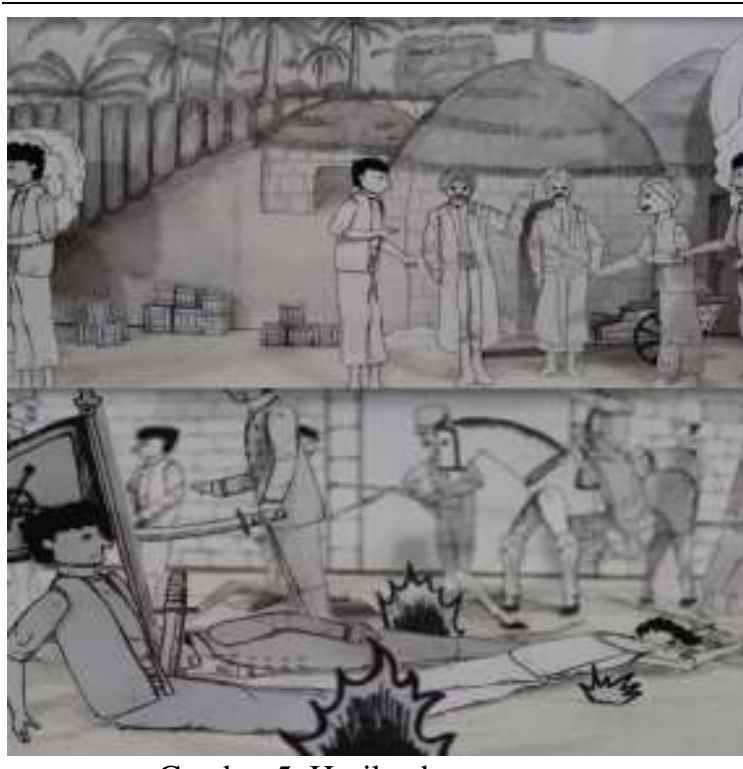

Gambar 5. Hasil gabungan scene

\section{Export}

Setelah semua scene digabungkan menjadi sebuah film animasi, tahap terakhir yang dilakukan adalah tahap export, dimana film animasi yang telah dibuat akan di-export file menjadi sebuah video. Format yang dipilih peneliti adalah H.264 (.mp4) denga kualitas HD 1080p.

Setelah proses produksi selesai,maka akan dilakukan pengujian. Proses pengujian dilakukan untuk setiap proses pembuatan animasi stop motion yang telah dibuat. Pengujian dilakukan melalui beberapa tahap sesuai dengan flowchart dibawah ini.

1. Animasi dan Pengambilan gambar

Proses ini dilakukan untuk mengatur objek yang akan dianimasikan sesuai dengan kebutuhan yang nantinya akan dijadikan stopmotion, yaitu pengambilan gambar dengan cara frame-by-frame dan dengan angle serta camera movement yang di sesuaikan. Jika pada proses testing tidak sesuai dengan keinginan maka dilakukan kembali proses

pengambilan gambar ini.

\section{Tunning}

Tahap tunning merupakan proses yang dilakukan untuk mempertajam warna gambar dari frame yang telah diambil. Dimana ketajaman warna gambar diatur didalam software Adobe Lightroom 6 . Tunning yang dilakukan antara lain adalah, brightness, contrast, dan curves.

3. Menyusun frame

Tahap ini merupakan proses yang dilakuan untuk menyatukan semua frame menjadi satu scene. Dimana frame-frame yang telah diambil pada tahap animasi akan dimasukan ke dalam software Adobe Premiere Pro CS6 kemudian di gabungkan menjadi sebuah scene.

\section{Testing}

Tahap Testing ini adalah tahap dimana hasil dari scene yang telah dibuat disesuaikan dengan storyboard yang telah ditentukan. Bila scene tersebut tidak sesuai dengan storyboard, maka kembali ke proses animasi untuk pengambilan ulang frame-frame stopmotion yang tidak sesuai tersebut.

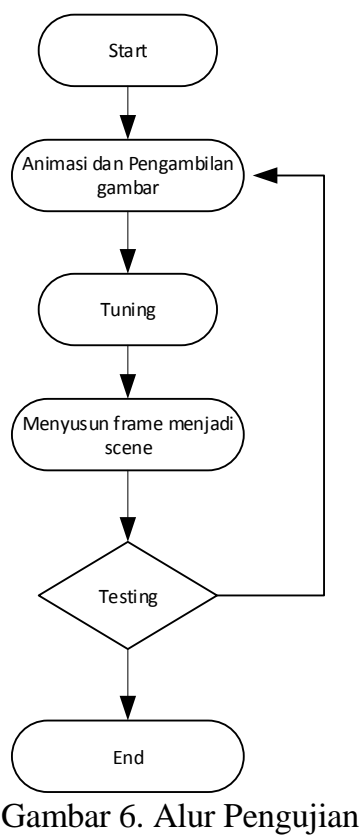

\section{Mastering Editing}

Salah satu kunci keberhasilan sebuah film atau video adalah proses editing. Editing video merupakan proses memilih, merangkai, menyusun ulang, dan memanipulasi video-video yang sudah direkam menjadi satu rangkaian video sehingga menjadi sebuah cerita utuh sebagaimana yang diinginkan sesuai konsep yang telah ditentukan. Ketika proses editinglah inilah gambar-gambar yang tidak penting dan tidak sesuai dengan konsep harus dihilangkan, susunan video harus dirangkai sesuai dengan durasi yang telah ditentukan, dan hal-hal yang kurang enak dilihat akan didedit dan ditambahkan, sehingga akhirnya menjadi rangkaian video utuh yang layak ditampilkan ke publik. Ketika proses editing, editor adalah orang yang paling bertanggung jawab terhadap kualitas sebuah video. Editor video harus mampu memahami maksud dan menerjemahkan keinginan sutradara. Berikut ini akan dibahas mengenai tugas-tugas mendasar seorang video editor.

\section{Menyunting Video}

Menyunting atau mengumpulkan video yang sudah diambil atau direkam merupakan hal pertama yang harus dilakukan oleh seorang video editor. Videovideo tersebut adalah hasil kerja para kameraman yang masih belum diolah, atau masih seusai dengan bentuk aslinya. Semua video yang berkaitan dengan naskah atau skenario harus dikumpulkan di dalam satu hardisk atau memori penyimpanan untuk memudahkan kinerja selanjutnya. 


\section{Menyusun Ulang}

Setelah semua video yang direkam selama proses shooting sudah dikumpulkan, editor harus menyusun ulang video-video tersebut sesuai dengan urutan sebagaimana tercantum dalam naskah atau skenario. Untuk memudahkan penyusunan ulang video-video tersebut, baisanya seorang editor akan berpatokan pada clapperboard (papan clip) yang biasanya dishooting di awal adegan. Dalam clapperboard tersebut terdapat catatan mengenai nomor urut adegan, scene, dan data-data lain mengenai pengambilan gambar. Dalam kegiatan menyusun ulang video, seorang editor harus memotong gambargambar yang tidak penting yang tidak termasuk ke dalam skenario.

\section{Memfilter Video}

Memfilter video berarti memilih gambar-gambar yang penting saja dan memberikan efek dan manipulasi grafik lainnya untuk meningkatkan tampilan video agar lebih enak dilihat, juga agar terhindar dari gambar-gambar yang mengganggu jalannya cerita. Selain itu, pada proses filterasi ini seorang editor juga harus mengatur transisi atau perpindahan dari satu adegan ke adegan lain menjadi lebih halus. Filter video juga berkaitan dengan tata cahaya pada gambar-gambar yang sudah dikumpulkan. Pada proses ini, editor harus memilah dan memilih kualitas video yang paling baik dan paling sempurna sesuai dengan naskah, sebab sebuah adegan biasanya harus mengalami beberapa kali take atau pengambilan gambar.

\section{Olah Suara}

Setelah memfilter video, tugas selanjutnya dari seorang editor video adalah mengolah suara, baik suara asli yang muncul ketika proses pengambilan gambar atau suara-suara tambahan yang perlu ditambahkan untuk memperkuat suasana video, misalnya sound effect atau musik. Dalam hal ini, seorang editor harus bekerja sama dengan penata suara dan penata musik agar menghasilkan suara yang sesuai dengan konsep.

\section{Membuat Titel}

Setelah semua gambar atau video sudah tersusun menjadi kesatuan cerita yang utuh dan sesuai dengan skenario, tugas selanjutnya adalah membuat titel pada video tersebut, yaitu informasi teks atau keterangan yang berkaitan dengan materi video.

\section{Finishing}

Setelah tahapan-tahapan di atas selesai dikerjakan, video editor harus melakukan pekerjaan akhirnya, yaitu tahap finishing. Pada tahap finishing, semua crew inti dari pembuatan video tersebut, mulai dari Sutradara, penata suara, penata artistik, dan crewcrew lainnya harus menyaksikan bersama video yang sudah diedit untuk memastikan bahwa video atau film yang sudah dihasilkan sudah terangkai dengan sempurna.

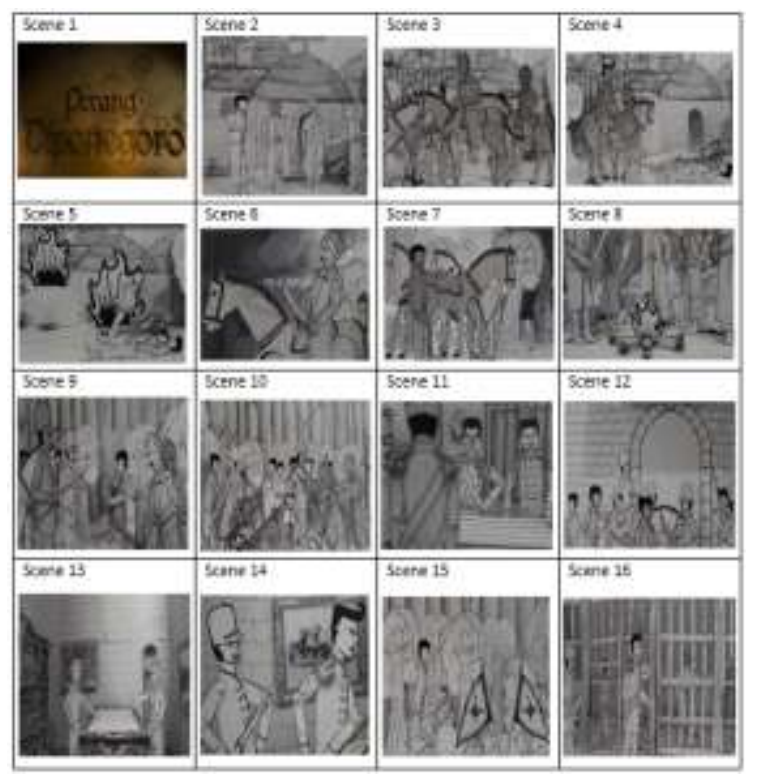

Gambar 7. Mastering Scene

Tahapan ini adalah tahapan terakhir yang dilakukan dalam pengerjaan film animasi ini. Rendering merupakan tahapan dimana dilakukannya pengkonversian atau proses untuk mengubah file project menjadi sebuah file yang dapat dijalankan di media lain. Pada karya penulis ini, file project yang dimaksud adalah hasil dari mixing dan editing pada Adobe Premiere, kemudian dirubah menjadi file video (movie trailer) sehingga dapat dijalankan di media/player lainnya (tidak hanya pada Adobe Premiere). Format video yang dihasilkan ditentukan pada tahapan rendering ini. Pada proyek akhir ini, video yang dihasilkan menggunakan format video quick time dengan menggunakan video codec H.2624 seperti yang sudah penulis sampaikan diatas.

\section{KESIMPULAN}

Film merupakan salah satu alat yang ampuh di tangan orang yang mempergunakannya secara efektif untuk sesuatu maksud terutama terhadap masyarakat kebanyakan dan juga anak-anak yang memang lebih banyak mengunakan aspek emosinya dibanding aspek rasionalnya, dan langsung berbicara ke dalam hati sanubari penonton secara meyakinkan. Film juga sangat membantu dalam proses pembelajaran, apa yang terpandang oleh mata dan terdengar oleh telinga, lebih cepat dan lebih mudah diingat daripada apa yang hanya dapat dibaca saja atau hanya didengar saja.

Berdasarkan penelitian penulis dalam perancangan karya film animasi stopmotion "Pangeran Diponegoro" yang telah dilakukan, maka dapat diambil beberapa kesimpulan, bahwa setelah dipertontonkan oleh para penonton bahwa film 
animasi Pangeran Diponegoro ini bagus untuk dijadikan sebagai media pembelajaran dan bisa dijadikan media edukasi dikalangan pelajar.

Semua teknik yang dilakukan untuk menerapkan sinematografi dalam pembuatan film animasi stopmotion "Pangeran Diponegoro" ini berhasil, berdasarkan survey pemirsa menyetujui bahwa sinematografi yang diterapkan sudah bagus. Semua testing berhasil dilakukan dengan hasil sesuai dengan storyboard yang dibuat. Sehingga menghasilkan film animasi stopmotion yang dapat menyampaikan nilai edukasi kepada audience dengan baik, dan audience dapat memahami isi dari film ini. Penulis menyadari masih banyak ke kurangan dalam proses merancang film animasi stopmotion Pangeran Diponegoro ini. Untuk itu penulis memberikan saran yang diharapkan dapat disempurnakan pada masa mendatang, diantaranya teknik animasi stopmotion ini dapat diterapkan dengan menggunakan media yang lebih baik dari kertas, seperti clay/lilin. Semua ini bertujuan agar animasi yang dibuat terlihat lebih hidup, lebih halus gerakannya, dan menghasilkan tampilan yang lebih menarik dan disukai oleh audience. Sebaiknya dalam pembuatan animasi stopmotion diperlukan desain storyboard yang detail, agar tidak terjadi kekeliruan pada saat pembuatan motion, angle camera, type shot, dan video translation. Pembuatan film stopmotion tidak lepas dari Fotografi dan sinematografi

\section{REFERENSI}

Arikunto, S. (2013). Prosedur Penelitian Suatu Pendekatan Praktik. Yogyakarta: Rineka Cipta.

Dhimas, A. (2013). Cara Mudah Merancang Storyboard Untuk Animasi Keren. Yogyakarta: Taka Publisher.

Hart, J. (2008). The Art Of Storyboard: A Filmmaker's Introduction. United States: Focal
Press.

Hendratman, H. (2017). The Magic of Adobe Premiere Pro. Jakarta: Informatika.

Lailatul Ristagama. (2014). Penciptaan Karya Animasi Kobarkan Semangat Bung Tomo. Pendidikan Seni Rupa, 2(2).

Naratama Rukmananda. (2014). Menjadi Sutradara Televisi. Jakarta: Grasindo.

Perisic, Z. (2013). Visual Effects Cinematography. United States: Focal Press.

Peter, C. (2016). Takdir - Riwayat Pangeran Diponegoro 1785-1855 (Edisi Peta Perang Jawa). Jakarta: Kompas.

Peterson, B. (2010). Understanding Exposure 3rd Edition. New York: Watson-Guptill Publications.

Ruslan, A. (2016). Perkembangan dan Konsep Animasi. Jakarta: Ghalia Indonesia.

W. Nugroho. (2011). Modul Training Produksi Film Animasi. Yogyakarta: Dreamlight World Media.

Wary, D. U. dan W. (2010). How to become a cameraman. Yogyakarta: Interprebook.

\section{PRODIL PENULIS}

Merupakan staff pengajar pada STMIK Nusa Mandiri Jakarta. Untuk bidang tulis menulis, selain buku Broadcasting Televisi Teori \& Praktik, sebelumnya ia juga aktif menulis artikel di BSI NewsLetter, Majalah SDA Asia dan Broadcast Magz. Antara komputer dan broadcasting inilah yang membuatnya menjadi tenaga pengajar yang mumpuni tanpa melupakan latar belakang di bidang komputer. Untuk beberapa tulisannya bisa dilihat pada web pribadinya di http://pojokspy.blogspot.com dimana banyak mahasiswa yang tertarik dan menerapkan materi perkuliahan yang didapat pada blog tersebut. 